\title{
Magnesium sulfate has sex-specific, dose-dependent vasodilator effects on preterm placental vessels
}

\author{
Clint Gray ${ }^{1,2,3^{*}}$, Mark H. Vickers ${ }^{3}$, Rebecca M. Dyson ${ }^{1,2,4}$, Clare M. Reynolds ${ }^{3}$ and Mary J. Berry ${ }^{1,2,5}$
}

\begin{abstract}
Background: Women at risk of preterm delivery receive magnesium sulfate $\left(\mathrm{MgSO}_{4}\right)$ in the pre-delivery phase to reduce their child's risk of neurodevelopmental complications associated with preterm birth. However, the mechanisms underpinning its placental vascular role remain uncertain.

Methods: The aim of this study was to examine $\mathrm{MgSO}_{4}$ action on vascular tone in male and female human placental vessels from term and preterm deliveries. Vessels were obtained from placental biopsy following birth at term (37-41 weeks) or preterm gestation ( $<36$ weeks of gestation). The vessels were mounted on a pressure myograph, pre-constricted with synthetic endoperoxide prostaglandin $\mathrm{PGH}_{2}(\mathrm{U} 46619)(0.1-100 \mu \mathrm{mol} / \mathrm{l})$, and percentage of relaxation was calculated following incubation with bradykinin. Experiments were carried out in the presence of $\mathrm{MgSO}_{4}(0.2 \mathrm{mmo} / \mathrm{l})$, $\mathrm{N}_{\psi}$-nitro-L-arginine methyl ester (L-NAME) $(0.1 \mathrm{mmol} / \mathrm{l})$, indomethacin $(10 \mu \mathrm{mol} / \mathrm{l})$, $\mathrm{Ca}^{2+}$-activated $\mathrm{K}^{+}$channel blocker TRAM-34 $(1 \mu \mathrm{M})$ and apamin $(3 \mu \mathrm{M})$ to assess mechanisms of vascular function. Vascular [calcium ions $\left(\mathrm{Ca}^{2+}\right)$ ] was analysed using a colorimetric calcium assay.
\end{abstract}

Results: Vasodilation in vessels from preterm males was significantly blunted in the presence of $\mathrm{MgSO}_{4}$ when compared to preterm female and term male and female vessels. Overall, $\mathrm{MgSO}_{4}$ was observed to differentially modulate placental vascular tone and vascular calcium concentrations in a sex-specific manner.

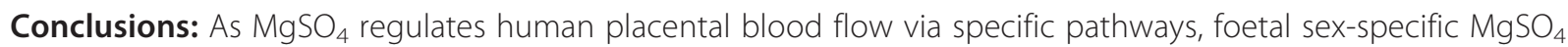
treatment regimes may be necessary. In an era of increasing awareness of individualised medicine, sex-specific effects may be of importance when developing strategies to optimise care in high-risk patients.

\section{Background}

Preterm birth is increasingly common, with recent global estimates suggesting that as many as $10 \%$ of infants (approximately 15 million infants per annum) are born prior to 37 weeks gestation [1, 2]. Although survival rates for preterm infants have improved, rates of cerebral palsy $(\mathrm{CP})$, neurodevelopmental delay and cognitive and behavioural or psychiatric issues are far more prevalent in infants born preterm when compared to term-born infants $[3,4]$. Although much attention has focused on infants born at the extremes of gestation, there appears

\footnotetext{
* Correspondence: c.gray@auckland.ac.nz

'Department of Paediatrics and Child Health, University of Otago, Wellington, New Zealand

${ }^{2}$ Centre for Translational Physiology, University of Otago, Wellington, New Zealand

Full list of author information is available at the end of the article
}

to be an effect of maturity at birth on later neurological function that extends the full spectrum of gestational age $[5,6]$.

$\mathrm{CP}$ is a permanent disorder of motor function due to disrupted or altered brain development. Its functional manifestations may evolve with time but there are no curative therapies currently available. The costs of CP are significant across a personal as well as global public health economic platform $[7,8]$. In an effort to reduce $\mathrm{CP}$ risk in children born prematurely, obstetric practice now includes treatment with intravenous magnesium sulphate $\left(\mathrm{MgSO}_{4}\right)$ for women at high risk of delivery before 30 weeks gestation [9]. While the overall efficacy of this approach has been well described, the number of women that needed treatment to prevent one case of $\mathrm{CP}$ is relatively high [10]. This suggests that $\mathrm{MgSO}_{4}$ either has an indirect role in the prevention of $\mathrm{CP}$ or that its 
effects are most beneficial to a subgroup of patients. Male disadvantage in survival and neurological outcomes in preterm infants has consistently been demonstrated $[11,12]$. However, the neuroprotective effects of antenatal $\mathrm{MgSO}_{4}$, in terms of sex specificity, have not yet been reported.

$\mathrm{MgSO}_{4}$ is a modulator of vascular tone [13, 14]. Therefore, the neuroprotective effects of $\mathrm{MgSO}_{4}$ may be partially mediated via improved placental perfusion, with improved nutrient transfer to the foetus, especially within the context of preterm labour. Maturational and sex-specific differences in vascular flow have already been identified in preterm infants. Newborn preterm males demonstrate increased microcirculatory flow compared to either preterm females or term-born infants of either sex [15]. Therefore, perinatal regulation of vascular tone may differ according to either gestational age and/or sex.

$\mathrm{MgSO}_{4}$ has been shown to freely cross the blood-brain barrier and maternal-placental-foetal interface. In adults, the physiological concentration of serum magnesium is 1.5 to $2.5 \mathrm{mEq} / \mathrm{l}(1.8$ to $3.0 \mathrm{mg} / \mathrm{dl})$, with approximately half inactivated, through binding to plasma proteins $[14,16,17]$. Therapeutic concentrations of maternal $\mathrm{MgSO}_{4}$ recommended for foetal neuroprotection are $1.8-3.5 \mathrm{mEq} / \mathrm{l}(2.1$ to $4.0 \mathrm{mg} / \mathrm{dl})$. It has been shown that following maternal $\mathrm{MgSO}_{4}$ treatment, $\mathrm{Mg}$ serum concentrations increase within $60 \mathrm{~min}$ and amniotic fluid concentrations increase after approximately $3 \mathrm{~h}$ [18]. Furthermore, foetal and maternal serum concentrations correlate well with foetal concentrations being elevated $24 \mathrm{~h}$ following maternal administration [19]. Despite well-established treatment regimes, the mechanisms governing $\mathrm{MgSO}_{4}$ and subsequent placental vascular function have yet to be defined. In the current study, experimental concentrations of $\mathrm{MgSO}_{4}$ were determined following a series of pilot studies in which the in vitro vasodilatory effects of $\mathrm{MgSO} 4$ were tested to the point of saturation where no further vasodilation was observed. Our study used a final vessel bath concentration of $3.6 \mathrm{mg} / \mathrm{dl}$ of $\mathrm{MgSO}_{4}$ as this was both within the therapeutic target range and had been shown to induce changes in vascular tone in vitro.

There are very few studies characterising the direct cardiovascular effects of $\mathrm{MgSO}_{4}$. In instrumented animal models, pregnant ewes treated with $\mathrm{MgSO}_{4}$ during late gestation have a reduction in maternal mean arterial pressure, increased uterine artery blood flow and increased foetal oxygenation, without an increase in foetal heart rate or blood pressure [20, 21]. However, a paucity of data exists with regard to the effects of $\mathrm{MgSO}_{4}$ on placental vascular function, and no studies have investigated the effect of $\mathrm{MgSO}_{4}$ on preterm human placental vasculature function.
Furthermore, the placenta is often generalised as an asexual organ and any influence of placental sex is routinely overlooked. However, the human placenta has distinct sexually dimorphic function. Male and female placentae have been shown to exhibit differences in global gene, protein expression, immune function, steroid profiles, growth factors, structure and overall function $[22,23,24,25,26]$. Sex-specific differences in vasomotor function may therefore be apparent in the placental vasculature as well as in the new born preterm human. The current study has used pressure myography to investigate the hypothesis that, in human placental chorionic plate vessels, there are sexually dimorphic differences in placental vascular function following $\mathrm{MgSO}_{4}$ treatment.

\section{Methods}

Approval for the study was granted by the University of Otago Human Ethics Committee (H13/058).

\section{Patient eligibility}

Eligible women admitted to the Delivery Suite of Wellington Hospital, Capital and Coast District Health Board, New Zealand, during the study period were approached for enrolment in the study. Eligible women were (i) carrying a singleton foetus with no known congenital infection or malformation or genetic or chromosomal abnormalities, (ii) of known gestational age (confirmed first trimester dating scan), (iii) no maternal history of pre-eclampsia or foetal growth restriction and (iv) able to read a patient information sheet and give written informed consent. The term cohort was comprised of women delivering between 37 and 41 weeks of gestation. The preterm cohort was comprised of women delivering at less than 36 weeks of gestation who had not received $\mathrm{MgSO}_{4}$ treatment prior to birth. Gestational age was ascertained by the mothers' attending lead maternity carer or admitting consultant obstetrician. All patients received obstetric care in accordance with routine clinical practice, and members of the study team were not involved in any aspect of the clinical care of any of the study subjects. The diagnostic criteria for the patients study eligibility was confirmed by an independent obstetrician following assessment at the time of admission and delivery. Term and preterm cohorts were further divided by infant sex (i.e. male term, female term, male preterm and female preterm) before statistical analysis. All maternal data were collected from patient records at the point of delivery.

\section{Sample collection}

Following delivery, the placentae were placed on ice pending biopsy collection. All biopsies were kept on ice for no longer than $15 \mathrm{~min}$ following delivery to dissection and myography cannulation. A $1-\mathrm{cm}^{3}$ placental 
biopsy was obtained using a placental measuring gauge to ensure all biopsies were collected from the same approximate region of the chorionic foetal side of the placenta. The biopsies were then placed in an ice-cold tissue collection buffer (TCB) $(119 \mathrm{mM} \mathrm{NaCl}, 4.7 \mathrm{mM}$ $\mathrm{KCl}, 1.6 \mathrm{nM} \mathrm{CaCl}, 2 \mathrm{H}_{2} \mathrm{O}, 24 \mathrm{NaHCO}_{3}, 1.18 \mathrm{KH}_{2} \mathrm{PO}_{4}$, $1.2 \mathrm{MgSO}_{4}, 0.05$ EDTA, 5.5 glucose at $\mathrm{pH} 7.4$ ) and remained on ice until studied.

\section{Vascular studies}

All chemicals and vasoactive drugs were purchased from Sigma-Aldrich (Auckland, NZ) unless stated otherwise. In brief, intact placental chorionic plate vessels (diameter $212 \pm 19 \mu \mathrm{m}$ ) were isolated from the placental biopsy and any remaining connective tissue removed under a dissecting microscope. The vessel segments were then mounted on a pressure myograph system (Living Systems Instrumentation, Burlington, VT, USA). The foetal vessels were attached to two glass microcannulae and secured with nylon thread sutures and then further aligned, so as not to stretch the vessel.

The vessel segments were pressurised to $70 \mathrm{mmHg}$ following the equilibration period of $30 \mathrm{~min}$ or cessation of vascular activity at $37{ }^{\circ} \mathrm{C}$ in TCB gassed with a mixture of $95 \% \mathrm{O}_{2}$ and $5 \% \mathrm{CO}_{2}$. The vessels were allowed to equilibrate under these conditions for $45 \mathrm{~min}$. Thereafter, cumulative concentration response curves were constructed for the synthetic analogue endoperoxide prostaglandin $\mathrm{H} 2\left(\mathrm{PGH}_{2}\right)$, U46619 (0.1-100 nmol/l). Changes in diameter at each U46619 concentration were compared to the initial vessel diameter as percent constriction and then normalised as percent maximum constriction. Following pre-constriction with U46619 - $\log$ concentration equal to the equivalent pEC80 (concentration equal to $80 \%$ of maximal response) and cumulative concentration curves were constructed using the endothelium-dependent vasodilator bradykinin (10 $\mathrm{pmol} / \mathrm{l}-1 \mu \mathrm{mol} / \mathrm{l})$. Following the initial experiments, bradykinin was used in preference to acetylcholine as it consistently produced larger and reproducible responses. Changes in the vessel diameter at each concentration were compared to the vessel diameter following pre-constriction with U46619 and then normalised as percentage relaxation. Following a washout, the concentrations response curves were performed in the presence of various vascular inhibitory drugs. Preliminary experiments determined the dose-dependent effect of $\mathrm{MgSO}_{4}$ $(0.05-0.25 \mathrm{mmol} / \mathrm{l})$ on isolated vessels. Concentrations of $\mathrm{MgSO}_{4}$ were initially determined by previously reported cord blood concentrations following maternal $\mathrm{MgSO}_{4}$ treatment [27]. A minimum of two vessels per placenta were analysed and averaged following vascular experimental protocols. All vasoactive drugs were applied extraluminally.
To analyse mediators of endothelium-dependent relaxation in human placental chorionic plate vessels, the three main vasodilatory pathways were examined (endothelial-derived hyperpolarising factors (EDHF), nitric oxide $(\mathrm{NO})$, prostacyclin $\left.\left(\mathrm{PGI}_{2}\right)\right)$. To block NO production, a non-specific NO synthase inhibitor L-NGnitroarginine methyl ester (L-NAME; $0.1 \mathrm{mmol} / \mathrm{l}$ ) was used. Indomethacin (INDO; $10 \mu \mathrm{mol} / \mathrm{l}$ ) was used to investigate any vasodilation derived from the cyclooxygenase pathway. The role of EDHF activity in human chorionic plate vessels is to use the adenosine triphosphate (ATP)-type calcium ions $\left(\mathrm{Ca}^{+}\right)$-activated $\mathrm{K}+$ channel blocker apamin $(3 \mu \mathrm{M})$ and intermediateconductance $\mathrm{Ca}_{2}^{+}$-activated $\mathrm{K}^{+}$channel blocker TRAM-34 $(1 \mu \mathrm{M})$. Inhibitors were used individually and in combination where stated.

\section{Vascular viability}

Alignment and vessel suture integrity was tested by increasing the intraluminal pressure to $70 \mathrm{mmHg}$, with further adjustment of the cannulae until the artery was observed to be aligned. Vessel functional integrity was assessed by washing the vessel for three 90-s washes with physiological salt solution (PSS) and preconstriction with U46619 (100 nmol/l) (pEC80). Vessels failing to reproduce consistent constrictions were considered non-viable and replaced with freshly excised vessels.

\section{Vascular $\left[\mathrm{Ca}^{2+}\right]$}

The placental chorionic plate vessels were solubilised and lysate cleared from solubilised tissue samples by centrifugation $(20,000 \times \mathrm{g}$ for $10 \mathrm{~min}) .\left[\mathrm{Ca}^{2+}\right]$ from the vessels was determined using a colorimetric Calcium Detection Kit (Abcam; Cambridge, UK) following the manufacturer's instructions.

\section{Statistical analysis}

All data are shown as means \pm SEM unless stated otherwise. All observations were made in a minimum of two vessels per placenta, and the average responses calculated. $n$ refers to the number of placenta used (two vessels per placenta). Concentration-relaxation curves were constructed using Prism software (GraphPad Software Inc., La Jolla, CA, USA.). Pressure myography and vascular calcium concentration data were analysed by using multifactorial analyses of variance (three-way ANOVA), with treatment, term and sex as the main factors. Where significant effects of factor and/or interactions were reported, Bonferroni multiple-comparison post hoc analysis was performed. $P$ values, $F$ values, and degrees of freedom are quoted for three-way ANOVA where appropriate. A Student $t$ test was employed for the analysis of basic maternal and neonatal biometrics (Table 1). A 
Table 1 Birth and placental weights refer to measurements obtained immediately after delivery

\begin{tabular}{|c|c|c|}
\hline \multirow[t]{2}{*}{ Characteristic } & $\begin{array}{l}\text { Term } \\
\text { (39-41 weeks) }\end{array}$ & $\begin{array}{l}\text { Preterm } \\
(32-<36 \text { weeks })\end{array}$ \\
\hline & $(n=20)$ & $(n=14)$ \\
\hline Maternal age (years) & $31.1 \pm 0.9$ & $29.1 \pm 1.5$ \\
\hline Maternal weight (kg) & $71 \pm 2.5$ & $67 \pm 2.4$ \\
\hline \multicolumn{3}{|l|}{ Maternal race or ethnic group (\%) } \\
\hline NZ European & 73 & 61 \\
\hline Chinese & 12 & 17 \\
\hline Pacific Islands & 15 & 22 \\
\hline Nulliparous (\%) & 0 & 0 \\
\hline Parity & $1.7 \pm 0.15$ & $1.8 \pm 0.1$ \\
\hline Twin gestation (\%) & 0 & 0 \\
\hline Smoking during pregnancy (\%) & 0 & 5 (1 patient) \\
\hline Alcohol use during pregnancy (\%) & 0 & 0 \\
\hline $\begin{array}{l}\text { MgS04 treatment during } \\
\text { pregnancy (\%) }\end{array}$ & 0 & 0 \\
\hline In vitro fertilisation (\%) & 8 & 0 \\
\hline \multicolumn{3}{|l|}{ Infant sex } \\
\hline Male & 10 & 7 \\
\hline Female & 10 & 7 \\
\hline \multicolumn{3}{|l|}{ Gestational age (weeks) } \\
\hline Male & $39^{2} \pm 0^{2}$ & $33^{6} \pm 1^{3}$ \\
\hline Female & $39^{6} \pm 0^{2}$ & $33^{5} \pm 1^{1}$ \\
\hline \multicolumn{3}{|l|}{ Birth weight (g) } \\
\hline Male & $3579 \pm 83^{*}$ & $2299 \pm 191$ \\
\hline Female & $3434 \pm 79^{*}$ & $1969 \pm 283$ \\
\hline \multicolumn{3}{|l|}{ Placental weight (g) } \\
\hline Male & $620 \pm 82^{*}$ & $540 \pm 72$ \\
\hline Female & $580 \pm 79^{*}$ & $517 \pm 91$ \\
\hline
\end{tabular}

Race or ethnic group was self-reported. $n=20$ subjects for term pregnancies ( $n=10$ male, $n=10$ female) and $n=14$ subjects for preterm pregnancies ( $n=7$ male, $n=7$ female). Data are shown as \pm SEM and percentages where stated

NS not significant

${ }^{*}$ Denotes statistical significance $(P<0.05)$ between groups by Student $t$ test

probability of $P<0.05$ was accepted as statistically significant. Statistical analysis was performed using SPSS version 21 (SPSS, Chicago, IL).

\section{Results}

\section{Maternal and neonatal biometrics}

There was no significant difference observed in maternal age, weight, parity, smoking and alcohol or substance use between groups (Table 1). Gestational age was significantly different between term and preterm births $(P<0.001)$. Mean gestational age in preterm males was not significantly different from preterm females (male, $33^{6} \pm 1^{3}$ weeks vs. female, $33^{5} \pm 1^{1}$ weeks), and no differences were observed between male and female term gestational age (male, $39^{2} \pm 0^{2}$ weeks vs. female, $39^{6} \pm 0^{2}$ weeks).

As expected, term male infants had a greater birth weight than female infants. Term infants had a greater birth weight than same-sex preterm infants (term male, $3579 \pm 84$ g vs. preterm male, $2299 \pm 191$ g; term female, $3434 \pm 79 \mathrm{~g}$ vs. preterm female, $1969 \pm 283 \mathrm{~g}, P<0.01$ for effect of sex and term vs. preterm). Term placentas were heavier than same-sex preterm placentas (term male, $620 \pm 82 \mathrm{~g}$ vs. preterm male, $540 \pm 72 \mathrm{~g}, P<0.05)$ and term female, $580 \pm 79 \mathrm{~g}$ vs. preterm female, $517 \pm 91 \mathrm{~g}$, $P<0.05)$. There was no effect of sex on placental weight within either gestational age group (Table 1). All women enrolled in the study delivered live-born singleton infants.

\section{Placental chorionic plate vessel responsiveness to Bradykinin}

Bradykinin (10 pmol/l-1 $\mu \mathrm{mol} / \mathrm{l})$ produced a concentrationdependent vasodilation in all vessels which was not different between groups or sex within group. U46619 (0.1-100 $\mu \mathrm{mol} / \mathrm{l})$ produced a concentration-dependent vasoconstriction in all vessels which was not different between groups (Fig. 1).

$\mathrm{MgSO}_{4}$ dose-response in placental chorionic plate vessels Following pre-constriction with U46619 (100 $\mu \mathrm{mol} / \mathrm{l})$, the vessels were treated with incremental concentrations of

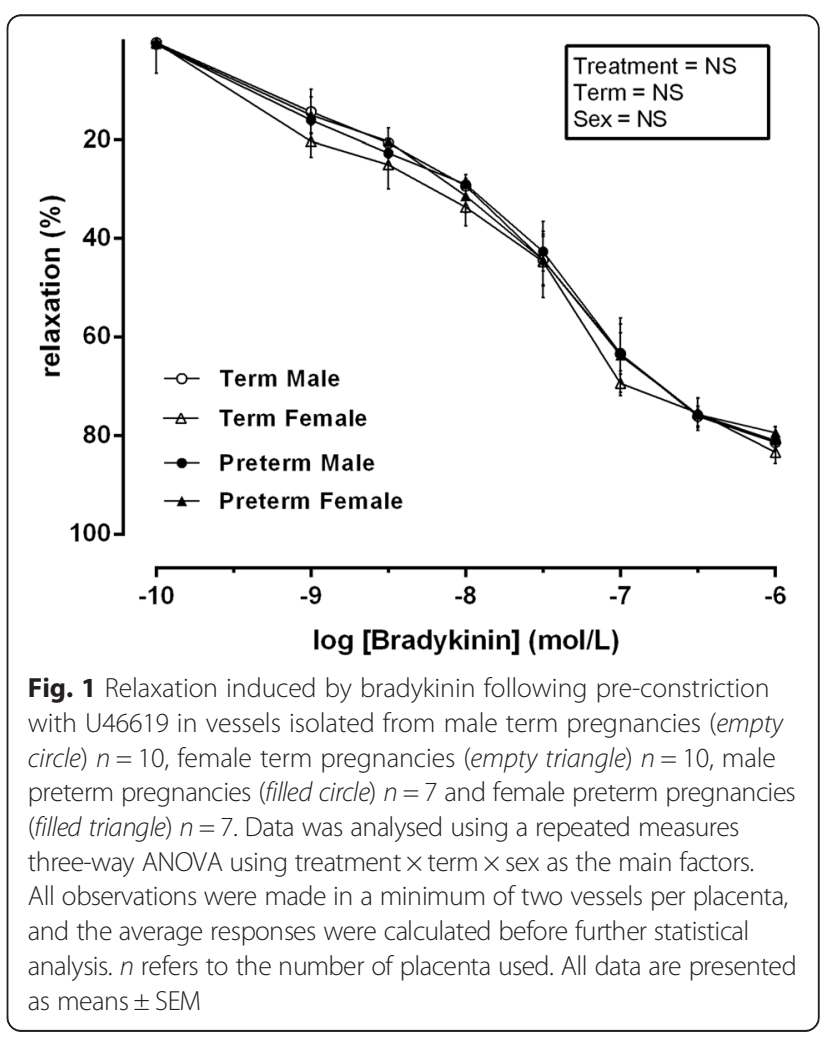


$\mathrm{MgSO}_{4}(0.05-0.25 \mathrm{mmol} / \mathrm{l})$. There was no overall effect of treatment, term or sex. However, a significant interaction effect (interaction effect = treatment $\times$ sex, $P=0.03, F=$ 11.61, $d f=2$ ) was observed. This is likely due to preterm male vessels having significantly less percentage of relaxation than all other groups following $\mathrm{MgSO}_{4}$ administration. Following post hoc analysis, the placental chorionic plate vessels from preterm male placentae had a reduced vasodilatory response $(P<0.01)$ compared to all other groups following $\mathrm{MgSO}_{4}$ treatment $(0.05,0.125,0.15$ and $0.20 \mathrm{mmol} / \mathrm{l})$. No further differences were observed at $\mathrm{MgSO}_{4}$ concentrations of $0.25 \mathrm{mmol} / \mathrm{l}$ as all vessels across all groups appeared to reach the point of saturation with further doses having no effect on percentage of relaxation (Fig. 2).

\section{Bradykinin-induced relaxation in placental chorionic plate vessels incubated with $\mathrm{MgSO}_{4}$}

Following pre-constriction with U46619 $(100 \mu \mathrm{mol} / \mathrm{l})$ and $\mathrm{MgSO}_{4}$ treatment $(0.2 \mathrm{mmol} / \mathrm{l})$, bradykinin-induced vasodilation was observed in a concentration-dependent manner in all vessels (Fig. 3). There was no overall effect of treatment, term or sex. However, a significant interaction effect (interaction effect $=$ treatment $\times \operatorname{sex}, P=0.02$, $F=9.376, d f=2)$ was observed. Following post hoc analysis, significantly less $(P<0.05)$ percentage of relaxation was observed in chorionic plate vessels from preterm male placental vessels when compared to all other groups.

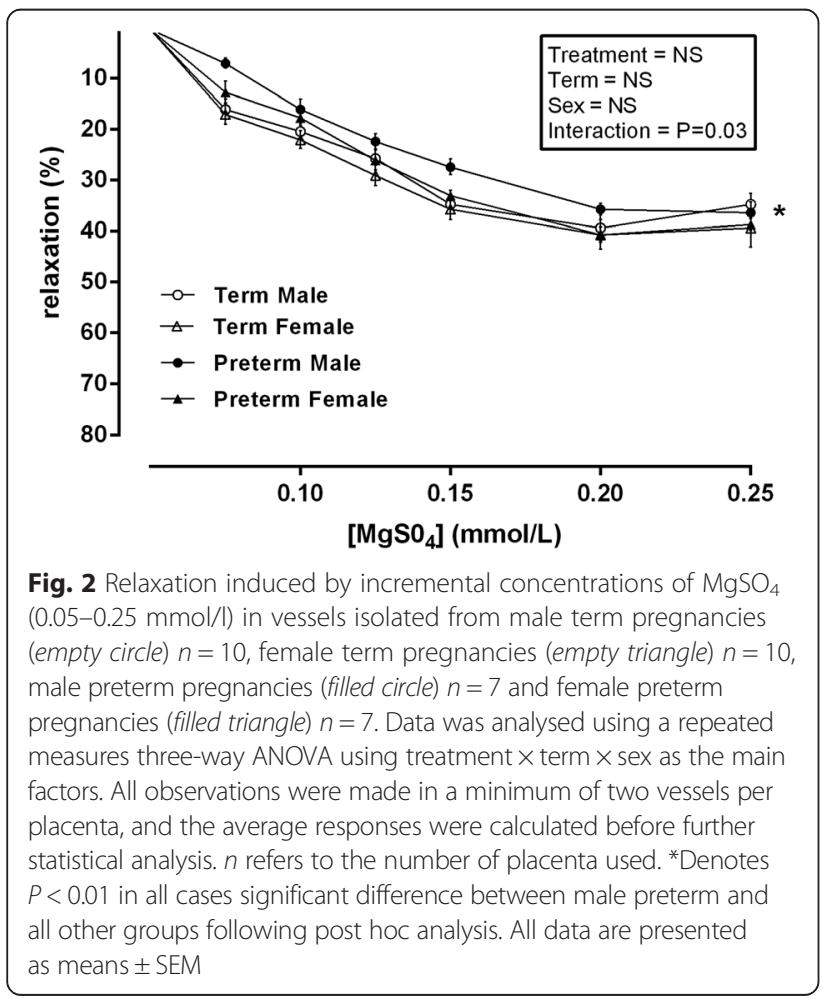

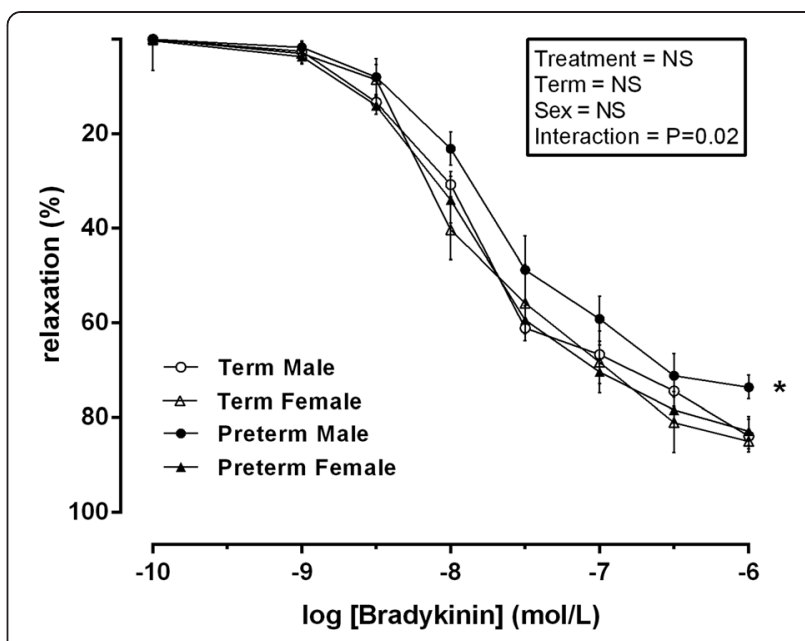

Fig. 3 Relaxation induced by bradykinin following pre-constriction with $\mathrm{U} 46619$ and following incubation with $\mathrm{MgSO}_{4}(0.2 \mathrm{mmol} / \mathrm{l})$ in vessels isolated from male term pregnancies (empty circle) $n=10$, female term pregnancies (empty triangle) $n=10$, male preterm pregnancies (filled circle) $n=7$ and female preterm pregnancies (filled triangle) $n=7$. Data was analysed using a repeated measures three-way ANOVA using treatment $\times$ term $\times$ sex as the main factors. All observations were made in a minimum of two vessels per placenta, and the average responses were calculated before further statistical analysis. $n$ refers to the number of placenta used. *Denotes $P<0.05$ in all cases significant difference between male preterm and all other groups following post hoc analysis. All data are presented as means \pm SEM

Bradykinin-induced relaxation in placental chorionic plate vessels incubated with INDO, L-NAME and $\mathrm{MgSO}_{4}$

Following pre-constriction with U46619 $(100 \mu \mathrm{mol} / \mathrm{l})$ and administration of $\mathrm{MgSO}_{4}(0.2 \mathrm{mmol} / \mathrm{l})$, INDO $(10 \mu \mathrm{mol} / \mathrm{l})$ and L-NAME $(0.1 \mathrm{mmol} / \mathrm{l})$, there was no overall effect of treatment, term or sex. However, a significant interaction effect (interaction effect $=$ treatment $\times \operatorname{sex}, P<0.01, F=8.213$, $d f=2$ ) was observed. Following post hoc analysis, significantly less $(P<0.01)$ percentage of relaxation was significantly attenuated in male preterm placental vessels when compared to female preterm vessels and both male and female term placental vessels at all -log concentrations of bradykinin $(P<0.01)$ (Fig. 4).

Bradykinin-induced relaxation in placental chorionic plate vessels incubated with TRAM-34, apamin, INDO and $\mathrm{MgSO}_{4}$

In the presence of $\mathrm{MgSO}_{4}(0.4 \mathrm{mmol} / \mathrm{l})$, TRAM-34 $(1 \mu \mathrm{M})$, apamin $(3 \mu \mathrm{M})$ and INDO $(10 \mu \mathrm{mol} / \mathrm{l})$ Bradykinin-induced vasodilatation did not differ between groups or sex within group (Fig. 5a).

Bradykinin-induced relaxation in placental chorionic plate vessels incubated with INDO and $\mathrm{MgSO}_{4}$

In the presence of INDO $(10 \mu \mathrm{mol} / \mathrm{l})$ and $\mathrm{MgSO}_{4}$ (0.2 $\mathrm{mmol} / \mathrm{l})$, bradykinin-induced vasodilatation was 


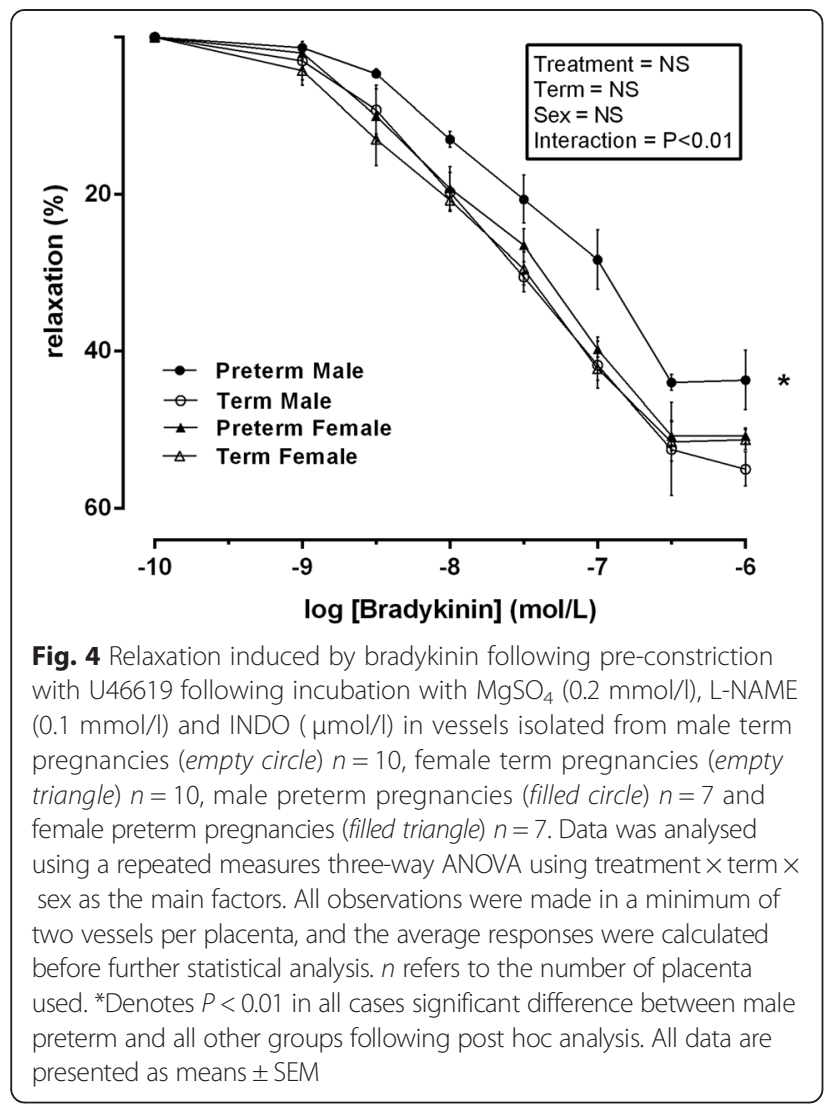

reduced in all groups, but did not differ between groups or sex within group (Fig. 5b).

Bradykinin-induced relaxation in placental chorionic plate vessels incubated with TRAM-34 and apamin and $\mathbf{M g S O}_{4}$ In the presence of $\mathrm{MgSO}_{4}(0.2 \mathrm{mmol} / \mathrm{l})$, TRAM-34 $(1 \mu \mathrm{M})$ and apamin $(3 \mu \mathrm{M})$ bradykinin-induced vasodilatation did not differ between group/sex within group (Fig. 5c).

\section{Vascular calcium concentration}

An overall effect of $\mathrm{MgSO}_{4}$ treatment was observed (main effect of treatment, $P<0.001, F=9.87, d f=1$ ) on vascular calcium concentration. $\mathrm{MgSO}_{4}$ significantly reduced vascular calcium concentration in male and female vessels of both groups $\left(\mathrm{MgSO}_{4}\right.$ treated vs. $\mathrm{MgSO}_{4}$ untreated; main effect of term, $P<0.001, F=5.35, d f=1)$. This equated to an average reduction in vascular calcium concentration of $\sim 40 \%$ (male preterm, $26.6 \pm 2.4$ vs. female preterm, $23.7 \pm 0.9 \mu \mathrm{g} / \mathrm{mg}$, male term, $22.5 \pm 2.1 \mu \mathrm{g} / \mathrm{mg}$ and female term, $23 \pm 2.2 \mu \mathrm{g} / \mathrm{mg}$ ) following $\mathrm{MgSO}_{4}$ treatment. An overall effect of sex could also be observed (main effect of sex, $P=0.05, F=18.15, d f=2$ ) in vascular calcium concentrations. In male preterm placental vascular tissue, calcium concentrations were significantly higher when compared to female preterm vascular tissue following $\mathrm{MgSO}_{4}$ (male, $9.2 \pm 1.5 \mu \mathrm{g} / \mathrm{mg}$ vs. female, $5.2 \pm 0.7 \mu \mathrm{g} / \mathrm{mg}$, male term, $6.1 \pm 2.0 \mu \mathrm{g} / \mathrm{mg}$, female term, $5.1 \pm 1.4 \mu \mathrm{g} / \mathrm{mg}$ ). No further effects of term or interactions were observed. Following post hoc analysis, intravascular calcium prior to $\mathrm{MgSO}_{4}$ treatment was significantly $(P<0.05)$ increased in male preterm vessels when compared to all other groups. Following $\mathrm{MgSO}_{4}$ treatment, male preterm vascular calcium concentrations were further significantly increased $(P<0.01)$ when compared to all other groups (Fig. 6).

\section{Discussion}

This is the first report of the sex-specific and dosedependent effect of $\mathrm{MgSO}_{4}$ on acute regulation of vascular reactivity in human placental chorionic plate vessels. Using small vessel pressure myography, we have demonstrated significant effects of sex on placental vasodilatation in response to $\mathrm{MgSO}_{4}$ treatment, specifically the vasculature of male preterm placentae having reduced vasodilatory responses to $\mathrm{MgSO}_{4}$ when compared with female placental vessels. Additionally, we provide evidence that these differences are likely, in part, due to competitive binding and inhibition of calcium channels and perturbation of EDHF pathways. Simultaneous analysis of vasomotor reactivity and $\left[\mathrm{Ca}^{2+}\right]_{\mathrm{i}}$ show that the specific mechanism of $\mathrm{MgSO}_{4}$-induced vasodilation is primarily caused by a decrease in vascular smooth muscle $[\mathrm{Ca} 2+]_{\mathrm{i}}$.

Consistent with published data, we observed a significant effect of $\mathrm{MgSO}_{4}$ on the modulation of vascular pathways related to smooth muscle function, specifically calcium homeostasis and EDHF function. This was manifest as a significant reduction in $\mathrm{MgSO}_{4}$-induced vasodilation in all vessels following inhibition of both $\mathrm{NO}$ and prostaglandin vasodilatory pathways. Although specific binding sites are not affected by $\mathrm{MgSO}_{4}$, competitive binding of non-specific calcium-binding sites are. Therefore, $\mathrm{MgSO}_{4}$ is likely to alter the efficacy of calcium to maintain a 'normal' maximum tension or vasodilation when applied to vascular smooth muscle by reducing the translocation of calcium into smooth muscle. Corroboratory evidence for this comes from our demonstration of a consistently higher vascular $\left[\mathrm{Ca}^{2+}\right]_{\mathrm{i}}$ in male preterm vessels when compared to female preterm placental chorionic plate vessels following incubation with $\mathrm{MgSO}_{4}$. This suggests that $\mathrm{MgSO}_{4}$ has a role in preventing free calcium uptake into the smooth muscle of these vessels, thus reducing basal vascular tone and promoting vasodilation. Moreover, it has been shown that $\mathrm{Ca}^{2+}$ blocks glutamate-activated $\mathrm{Ca}^{2+}$ and may stabilise fluctuations in blood pressure and heart rate and increase cerebral blood flow. Abad et al. previously reported $\mathrm{MgSO}_{4}$ treatment in preeclamptic pregnant women modified both Ca-ATPase activity and 

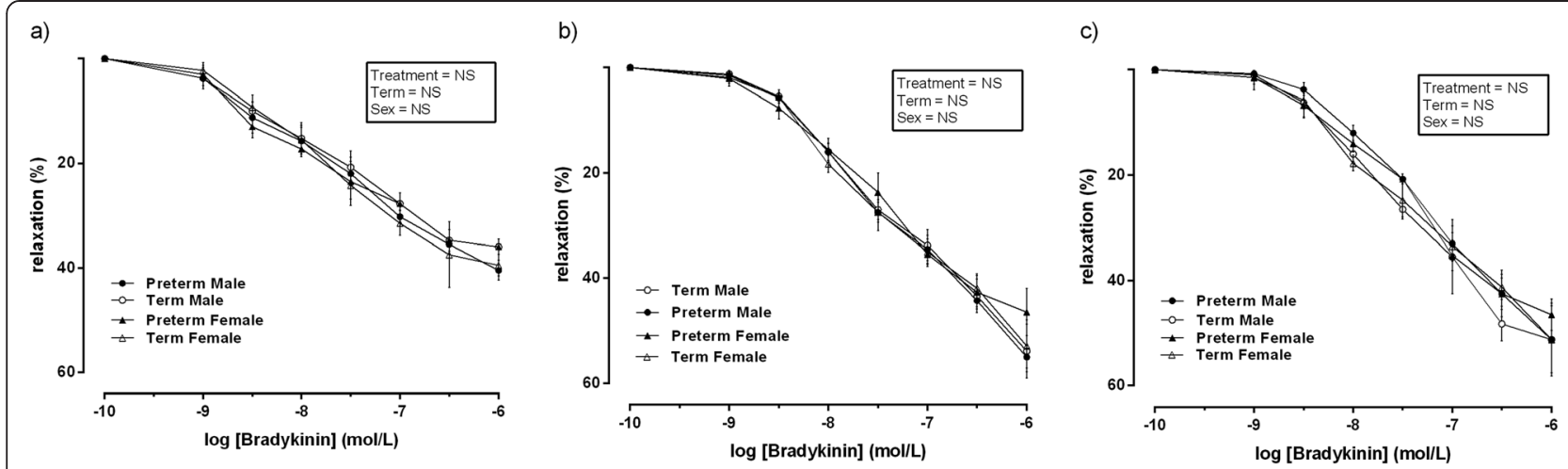

Fig. 5 a Relaxation induced by bradykinin following pre-constriction with U46619 following incubation with $\mathrm{MgSO}_{4}(0.2 \mathrm{mmo} / \mathrm{l})$, INDO (10 $\mu$ mol/l), TRAM-34 (1 $\mu \mathrm{M})$ and apamin $(3 \mu \mathrm{M})$ in vessels isolated from male term pregnancies (empty circle) $n=10$, female term pregnancies (empty triangle) $n=10$, male preterm pregnancies (filled circle) $n=7$ and female preterm pregnancies (filled triangle) $n=7$. Data was analysed using a repeated measures three-way ANOVA using treatment $\times$ term $\times$ sex as the main factors. All observations were made in a minimum of two vessels per placenta, and the average responses were calculated before further statistical analysis. $n$ refers to the number of placenta used. All data are presented as means \pm SEM. b Relaxation induced by bradykinin following pre-constriction with U46619 following incubation with MgSO4 (0.2 mmol/) and indomethacin $(10 \mu \mathrm{mol} / \mathrm{l})$ in vessels isolated from male term pregnancies (empty circle) $n=10$, female term pregnancies (empty triangle) $n=10$, male preterm pregnancies (filled circle) $n=7$ and female preterm pregnancies (filled triangle) $n=7$. Data was analysed using a repeated measures three-way ANOVA using treatment $x$ term $x$ sex as main factors. All observations were made in a minimum of two vessels per placenta and the average responses calculated before further statistical analysis. $n$ refers to the number of placenta used. All data are means \pm SEM. $\mathbf{c}$ Relaxation induced by bradykinin following pre-constriction with U46619 following incubation with $\mathrm{MgSO}_{4}(0.2 \mathrm{mmol} / \mathrm{l})$, TRAM-34 (1 $\left.\mu \mathrm{M}\right)$ and Apamin $(3 \mu \mathrm{M})$ in vessels isolated from male term pregnancies (empty circle) $n=10$, female term pregnancies (empty triangle) $n=10$, male preterm pregnancies (filled circle) $n=7$ and female preterm pregnancies (filled triangle) $n=7$. Data was analysed using a repeated measures three-way ANOVA using treatment $x$ term $\times$ sex as the main factors. All observations were made in a minimum of two vessels per placenta and the average responses calculated before further statistical analysis. $n$ refers to the number of placenta used. All data are presented as means \pm SEM

reduced lipid peroxidation concentrations in red blood cell membranes. They concluded that the inhibitory action of $\mathrm{MgSO}_{4}$ on lipid peroxidation accounts for an increase in Ca-ATPase activity to normotensive pregnancy concentrations. They hypothesised that this increases vasodilatation and potentially decreases maternal peripheral vascular resistance which may explain reduction in preeclamptic seizures [28]. The significant decrease in vasoconstriction and $\left[\mathrm{Ca}^{2+}\right]$ in female vessels and decreased effects of $\mathrm{MgSO}_{4}$ observed on male placental vessels shows that a decreased capacity to regulate $\left[\mathrm{Ca}^{2+}\right]_{\mathrm{i}}$ homeostasis and impairment of $\mathrm{Ca}^{2+}$ transport are likely to play a role in the sex-specific differences of $\mathrm{MgSO}_{4}$-induced relaxation of placental vessels. This may be a key determinant in restoring optimal perfusion and nutrient supply to a foetus at risk of imminent preterm birth, whether consequent on preterm labour reducing placental perfusion or as a consequence of whichever pathological process initiated the need for 'elective' preterm delivery.

The current study has shown that vasodilatory responses to bradykinin in small placental chorionic plate vessels isolated from term and preterm were similar across group and sex when vascular inhibition of NO generation and $\mathrm{PGI}_{2}$ alone was performed. These results may indicate that in the absence of $\mathrm{NO}, \mathrm{PGI}_{2}$ pathways may mediate vasodilatation. In the endothelium, $\mathrm{MgSO}_{4}$ has been shown to increase prostaglandin $\mathrm{I}_{2}$ production and increases NO production causing vasodilation [29]. Although we report no difference in response to bradykinin in untreated vessels, analysis revealed differences in endothelium-dependent vasoresponsiveness to bradykinin in vessels from term vs. preterm groups following incubation with L-NAME, indomethacin, TRAM-34, apamin and $\mathrm{MgSO}_{4}$. The response to bradykinin in isolated vessels from term and preterm placentas shared some similarities, in that responses were unaffected by partial depolarisation. However, relaxation was significantly reduced by blockade of the $\mathrm{NO}$ and $\mathrm{PGI}_{2}$ pathways in male and female preterm placental vessels. This may indicate a reduced depolarization potential to EDHF in male preterm placental vessels.

Recommended clinical obstetric practice in the Capital and Coast District Health Board, Wellington, is to restrict the use of $\mathrm{MgSO}_{4}$ when delivery is anticipated at, or below, 30 weeks of gestation although use in other centres is more liberal $[9,30]$. For this reason, we were able to study a population of women who delivered prematurely, yet did not receive $\mathrm{MgSO}_{4}$ as part of their routine care. Whether the sex-specific effects of $\mathrm{MgSO}_{4}$ would be greater at a lesser gestation is therefore unknown and may be difficult to answer given the widespread use of $\mathrm{MgSO}_{4}$ in this clinical population. Although, the mechanisms underlying the sex-specific vascular function in preterm placentae could not be fully elucidated in the current study. We have demonstrated 


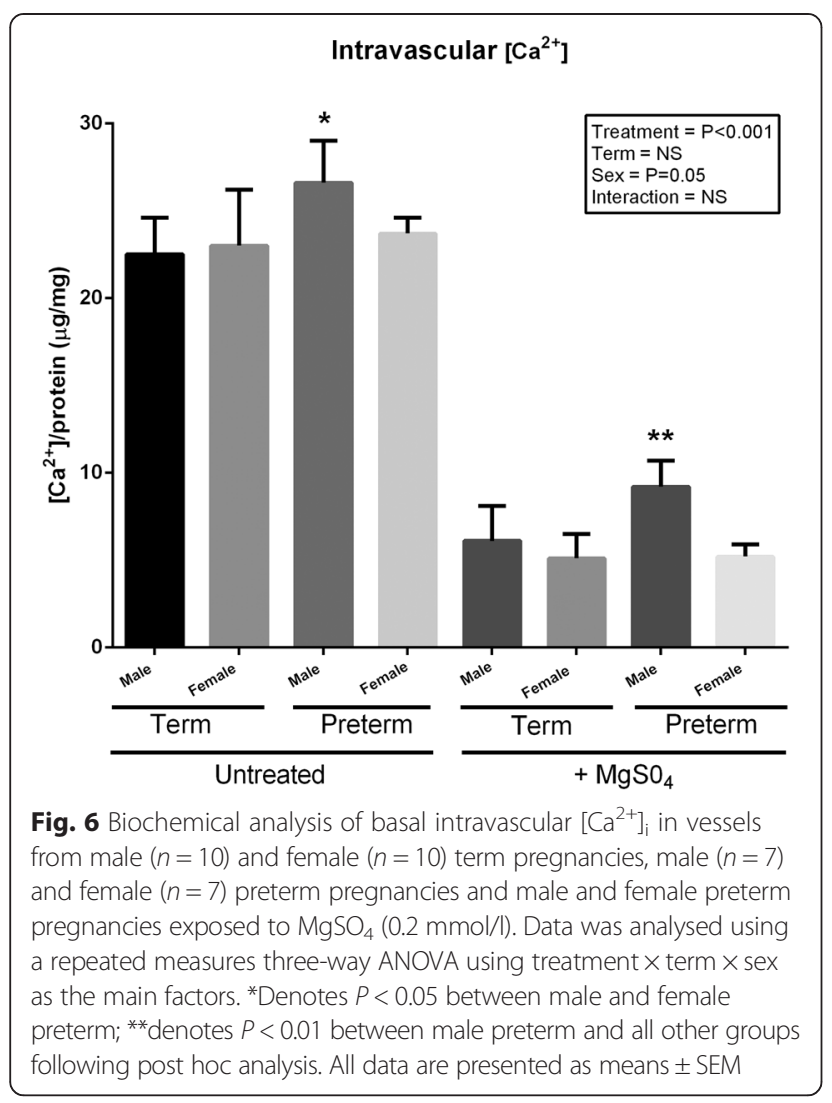

that $\mathrm{MgSO}_{4}$ treatment at currently recommended therapeutic concentrations improves vascular responsiveness in placental vessels in both term and preterm placentae in a dose-dependent manner. Furthermore, this study provides direct evidence that the mechanism of $\mathrm{MgSO}_{4}$-induced relaxation in placental vessels involves a reduction in vascular $\left[\mathrm{Ca}^{+}\right]_{\mathrm{i}}$ and more importantly is significantly attenuated in the placentae of preterm males compared to preterm females. We therefore promote the concept that it is no longer acceptable to pool placental data or make assumptions of placental function without acknowledging the specific sex of the placenta. Accordingly, future studies of placental function or perinatal intervention must be adequately powered to account for placental sex as an independent factor when considering experimental design and statistical analysis.

$\mathrm{MgSO}_{4}$ has been previously shown to increase vascular relaxation in the aorta, resistance vessels and placental perfusion in animal models and humans [31]. Similarly, our results suggest that perfusion of the preterm placenta is improved by maternal $\mathrm{MgSO}_{4}$ treatment and is likely due to increased plasma $\mathrm{Mg}$ resulting in competitive inhibition of calcium channels. This suggests that the effect of increased $\mathrm{Mg}^{+}$competitively inhibiting $\mathrm{Ca}^{+}$entry into the smooth muscle is the primary causal factor in mediating vasodilation. Our findings support the hypothesis that the more specific action of $\mathrm{MgSO}_{4}$ on placental vascular function may primarily be governed by alterations in calcium homeostasis [32, 33]. Furthermore, the significant reductions in male preterm placental vasodilatory capacity is caused by EDHF-induced vasodilation and altered vascular $\left[\mathrm{Ca}^{+}\right]_{\mathrm{i}}$ homeostasis and is likely to be the major mechanism involved in these sex-specific differences of $\mathrm{MgSO}_{4}$-induced relaxation in preterm placentae.

\section{Conclusions}

In summary, we have examined the effects of $\mathrm{MgSO}_{4}$ on vascular tone in male and female placental vessels from term and preterm deliveries. Our results demonstrate that male and female foetuses may employ sex-specific survival strategies when presented with adverse maternal environments and associated pregnancy complications. Data presented here provide evidence that the placenta functions in a sex-specific manner and the overall neuroprotective effects of $\mathrm{MgSO}_{4}$ are most marked in preterm females as their placental bed is able to maximally relax in response to $\mathrm{MgSO}_{4}$, thus improving foetal nutrient delivery and gas exchange in the peri-partum period. This could be a major contributing factor in explaining that the sex-specific differences in perinatal morbidity and mortality may be due to sexually dimorphic placental adaptations during pregnancy and the relatively high neonatal morbidity and ongoing male disadvantage seen in Neonatal Units. However, clinical trials of $\mathrm{MgSO}_{4}$ have not yet addressed sex-specific long-term outcomes. In this era of pharmacogenetic where individualised drug therapy is the focus of much research interest, future advances in perinatal care need to be powered appropriately to incorporate the effect of foetal and therefore placental sex on outcomes of interest.

\section{Abbreviations}

ATP: adenosine triphosphate; $\mathrm{Ca}^{2+}$ : calcium ions; CP: cerebral palsy; EDHF: endothelial-derived hyperpolarizing factor; INDO: indomethacin; L-NAME: $\mathrm{N}_{\psi}$-nitro-L-arginine methyl ester; $\mathrm{MgSO}_{4}$ : magnesium sulphate; pEC80: concentration required to produce $80 \%$; $\mathrm{PGH}_{2}$ : prostaglandin $\mathrm{H} 2$; $\mathrm{PGI}_{2}$ : prostacyclin; PSS: physiological salt solution; TCB: tissue collection buffer; TRAM-34: $\mathrm{Ca}^{2+}$-activated $\mathrm{K}^{+}$channel blocker; U46619: synthetic endoperoxide prostaglandin $\mathrm{PGH}_{2}$.

\section{Competing interests}

The authors declare that they have no competing interest.

\section{Authors' contributions}

CG and MJB designed the experiments. CG analysed the data. CG performed the experiments. MJB enrolled the patients and collected maternal data. CG and MHV contributed the equipment and consumables. CG and MJB wrote the paper. MHV, RMD, and CMR critically evaluated the paper. All authors read and approved the final manuscript.

\section{Acknowledgements}

The authors would like to acknowledge the staff of the Wellington Hospital Delivery Suite and Neonatal Intensive Care Units for their assistance, patient recruitment and data collection. The authors would like to thank Dr. Joanna Stanley for the expert technical advice. Dr. Clint Gray was supported by a Lottery Health Research Fellowship, Faculty Development Research Funding (FDRF) and Gravida: National Centre for Growth and Development. 


\section{Author details}

${ }^{1}$ Department of Paediatrics and Child Health, University of Otago, Wellington, New Zealand. ${ }^{2}$ Centre for Translational Physiology, University of Otago, Wellington, New Zealand. ${ }^{3}$ Gravida: National Centre for Growth and Development, Liggins Institute, University of Auckland, Auckland, New Zealand. ${ }^{4}$ Department of Paediatrics, Graduate School of Medicine and IHMRI, University of Wollongong, Wollongong, NSW, Australia. ${ }^{5}$ Capital and Coast District Health Board, Wellington, New Zealand.

\section{Received: 1 July 2015 Accepted: 28 October 2015}

\section{Published online: 04 November 2015}

\section{References}

1. Blencowe H, Cousens S, Oestergaard MZ, Chou D, Moller AB, Narwal R, et al. National, regional, and worldwide estimates of preterm birth rates in the year 2010 with time trends since 1990 for selected countries: a systematic analysis and implications. Lancet. 2012;379(9832):2162-72.

2. Doyle LW. Evaluation of neonatal intensive care for extremely low birth weight infants in Victoria over two decades: I. Effectiveness. Pediatrics. 2004;113(3 Pt 1):505-9.

3. Marlow N, Wolke D, Bracewell MA, Samara M. Neurologic and developmental disability at six years of age after extremely preterm birth. N Engl J Med. 2005;352(1):9-19.

4. Jarjour IT. Neurodevelopmental outcome after extreme prematurity: a review of the literature. Pediatr Neurol. 2015;52:143-52.

5. Espel EV, Glynn LM, Sandman CA, Davis EP. Longer gestation among children born full term influences cognitive and motor development. PLoS ONE. 2014;9(11), e113758. doi:10.1371/journal.pone.0113758.

6. Talge NM, Holzman C, Wang J, Lucia V, Gardiner J, Breslau N. Late-preterm birth and its association with cognitive and socioemotional outcomes at 6 years of age. Pediatrics. 2010;126:1124-31.

7. Behrman RE, Stith Butler A. Committee on Understanding Premature Birth and Assuring Healthy Outcomes. Preterm birth: causes, consequences, and prevention. The National Academies Collection. Washington (DC): National Academies Press (US); 2007

8. Gilbert WM, Nesbitt TS, Danielsen B. The cost of prematurity: quantification by gestational age and birth weight. Obstet Gynecol. 2003;102(3):488-92

9. Antenatal Magnesium Sulphate for Neuroprotection Guideline Development Panel. Antenatal magnesium sulphate prior to preterm birth for neuroprotection of the fetus, infant and child: National clinical practice guidelines. Adelaide: the University of Adelaide; 2010. ISBN 978-0-86396720-7.

10. Doyle LW, Crowther CA, Middleton P, Marret S, Rouse D. Magnesium sulphate for women at risk of preterm birth for neuroprotection of the fetus. Cochrane Database Syst Rev. 2009;1, CD004661.

11. Ambalavanan N, Carlo WA, Tyson JE, Langer JC, Walsh MC, Parikh NA. Outcome trajectories in extremely preterm infants. Pediatrics. 2012;130:e115-25.

12. Kent AL, Wright IM, Abdel-Latif ME. Mortality and adverse neurologic outcomes are greater in preterm male infants. Pediatrics; 2012;129:124-31.

13. Altura BM, Altura BT, Carella A, Gebrewold A, Murakawa T, Nishio A. Mg2 +-Ca2+ interaction in contractility of vascular smooth muscle: Mg2+ versus organic calcium channel blockers on myogenic tone and agonist-induced responsiveness of blood vessels. Can J Physiol Pharmacol. 1987;65(4):729-45.

14. Euser AG, Cipolla MJ. Magnesium sulfate for the treatment of eclampsia. Stroke. 2009:40:1169-75.

15. Stark MJ, Clifton VL, Wright IM. Sex-specific differences in peripheral microvascular blood flow in preterm infants. Pediatr Res. 2008;63:415-9.

16. Donaldson JO. Does magnesium sulfate treat eclamptic convulsions? Clin Neuropharmacol. 1986:9(1):37-45

17. Taber EB, Tan L, Chao CR, Beall MH, Ross MG. Pharmacokinetics of ionized versus total magnesium in subjects with preterm labor and preeclampsia. Am J Obstet Gynecol. 2002;186(5):1017-21.

18. Hallak M, Cotton DB. Transfer of maternally administered magnesium sulfate into the fetal compartment of the rat: assessment of amniotic fluid, blood, and brain concentrations. Am J Obstet Gynecol. 1993;169(2 Pt 1):427-31.

19. Hallak M, Berry SM, Madincea F, Romero R, Evans MI, Cotton DB. Fetal serum and amniotic fluid magnesium concentrations with maternal treatment. Obstet Gynecol. 1993;81(2):185-8.
20. Bolan JC, Craft Jr JB, Patch JH, Woolf WA, Fabro S, Lahijani J, et al. Pharmacokinetics of magnesium sulfate in the sheep model. Pediatr Pharmacol. 1985;5(3):189-99.

21. Reynolds JD, Chestnut DH, Dexter F, McGrath J, Penning DH. Magnesium sulfate adversely affects fetal lamb survival and blocks fetal cerebral blood flow response during maternal hemorrhage. Anesth Analg. 1996:83(3):493-9.

22. Clifton VL. Sex and the human placenta: mediating differential strategies of fetal growth and survival. Placenta. 2010;31:S33-9.

23. Gabory A, Roseboom TJ, Moore T, Moore LG, Junien C. Placental contribution to the origins of sexual dimorphism in health and diseases: sex chromosomes and epigenetics. Biol Sex Differ. 2013;4(1):5.

24. Muralimanoharan S, Maloyan A, Myatt L. Evidence of sexual dimorphism in the placental function with severe preeclampsia. Placenta. 2013;34(12):1183-9.

25. Myatt L, Muralimanoharan S, Maloyan A. Effect of preeclampsia on placental function: influence of sexual dimorphism, microRNA's and mitochondria. Adv Exp Med Biol. 2014;814:133-46.

26. Walker MG, Fitzgerald B, Keating S, Ray JG, Windrim R, Kingdom JCP. Sex-specific basis of severe placental dysfunction leading to extreme preterm delivery. Placenta. 2012;33(7):568-71.

27. Pruett KM, Kirshon B, Cotton DB, Adam K, Doody KJ. The effects of magnesium sulfate therapy on Apgar scores. Am J Obstet Gynecol. 1988;159(5):1047-8.

28. Abad C, Teppa-Garran A, Proverbio T, Pinero S, Proverbio F, Marin R. Effect of magnesium sulphate on the calcium-stimulated adenosine triphosphate activity and lipid peroxidation of red blood cell membranes from preeclamptic women. Biochem Pharmacol. 2005;70(2005):1634-41.

29. O'Brien WF, Williams MC, Benoit R, Sawai SK, Knuppel RA. The effect of magnesium sulfate infusion on systemic and renal prostacyclin production. Prostaglandins. 1990;40(5):529-38.

30. Conde-Agudelo A, Romero R. Antenatal magnesium sulfate for the prevention of cerebral palsy in preterm infants less than 34 weeks' gestation: a systematic review and metaanalysis. Am J Obstet Gynecol. 2009;200(2009):595-609.

31. Longo M, Jain V, Vedernikov YP, Hankins GDV, Garfield RE, Saade GR. Effects of L-type Ca2+-channel blockade, K+-channel opening and nitric oxide on human uterine contractility in relation to gestational age and labour. Mol Hum Reprod. 2003;9(3):159-64

32. Shaul PW, Mimouni F, Tsang RC, Specker BL. The role of magnesium in neonatal calcium homeostasis: effects of magnesium infusion on calciotropic hormones and calcium. Pediatr Res. 1987;22(3):319-23.

33. Smith LG, Burns PA, Schanler RJ. Calcium homeostasis in pregnant women receiving long-term magnesium sulfate therapy for preterm labor. Am J Obstet Gynecol. 1992;167(1):45-51.

\section{Submit your next manuscript to BioMed Central and take full advantage of:}

- Convenient online submission

- Thorough peer review

- No space constraints or color figure charges

- Immediate publication on acceptance

- Inclusion in PubMed, CAS, Scopus and Google Scholar

- Research which is freely available for redistribution 